\title{
Correlation of Peripheral Nerve Fiber Loss and Trinucleotide Repeats in Machado-Joseph Disease
}

\author{
Bing-wen Soong and Kon-ping Lin
}

\begin{abstract}
Background: Machado-Joseph disease (MJD) is a dominantly inherited cerebellar ataxia associated with spasticity, ophthalmoplegia and dystonia. There has been no report of electrophysiological or histological alterations of the peripheral nervous system in patients with MJD. Methods: Four patients with MJD were identified by polymerase chain reaction. The peripheral nerves of these patients were subjected to electrophysiological testing and histological study. Correlation analyses were made between various clinical parameters and the electrophysiological and histological changes. Results: Electrophysiological studies demonstrated a marked reduction of sensory action potential, acute denervation changes on needle EMG, as well as mild decrease in the compound motor action potential. Light microscopy of the sural nerves revealed clear loss of myelinated fibers, and morphometry studies showed a loss of large myelinated fibers. Moreover, the severity of these pathological changes was found to be related to the CAG repeat length in the MJD gene. Conclusion: Our findings indicated that the peripheral nervous system was frequently affected in patients with MJD. These findings were similar to those seen in Friedreich's ataxia, suggesting a loss of sensory and motor fibers probably following a lesion of the dorsal root ganglion and the anterior horns in the spinal cord. Furthermore, the number of CAG repeats seems to have an inverse relationship to the extent of pathological changes of the peripheral nerves.
\end{abstract}

\begin{abstract}
RÉSUMÉ: Corrélation entre la perte des fibres nerveuses périphériques et les répétitions de trinucléotides dans la maladie de Machado-Joseph. Introduction: La maladie de Machado-Joseph (MMJ) est une ataxie cérébelleuse se manifestant par de la spasticité, une ophtalmoplégie et de la dystonie, et dont l'hérédité est dominante. Aucune atteinte électrophysiologique ou histologique du système nerveux périphérique n'a été rapportée chez ces patients. Méthodes: Le diagnostic a été confirmé par la réaction d'amplification en chaîne (PCR) chez quatre patients atteints de la MMJ. Nous avons fait des études électrophysiologiques et histologiques des nerfs périphériques de ces patients, ainsi que des analyses de corrélation entre les différents paramètres cliniques et les changements électrophysiologiques et histologiques. Résultats: Les études électrophysiologiques ont montré une réduction marquée du potentiel d'action sensitif, une dénervation aiguë à l'EMG ainsi qu'une légère diminution du potentiel d'action moteur composé. La microscopie optique du nerf sural a montré une perte très nette des fibres myélinisés et des études morphométriques ont montré une perte des grosses fibres myélinisées. De plus, la sévérité de ces changements anatomopathologiques était reliée à la longueur de la répétition CAG dans le gène de la MMJ. Conclusion: Nos observations indiquent que le système nerveux périphérique est fréquemment atteint chez les patients qui ont la MMJ. Ces observations sont semblables à ce qu'on note dans l'ataxie de Friedreich, suggérant qu'une perte de fibres sensitives et motrices survient suite à une lésion du ganglion dorsal et de la corne antérieure de la moelle épinière. De plus, il semble exister une relation inverse entre le nombre de répétitions CAG et l'étendue des changements anatomopathologiques dans les nerfs périphériques.
\end{abstract}

Can. J. Neurol. Sci. 1998; 25: 59-63

The spinocerebellar ataxias are a heterogeneous group of neurodegenerative disorders characterized by variable degrees of cerebellar dysfunction.' Among them, Machado-Joseph disease (MJD, MIM 109150) is characterized by cerebellar ataxia, pyramidal signs, and progressive external ophthalmoplegia, and is associated to variable degrees with symptoms such as bulging eyes and dystonia.' Clinical heterogeneity in the presentation of MJD is common between as well as within families. ${ }^{1,2}$ Pathologically, MJD is characterized by degeneration of the spinocerebellar tracts, dentate nuclei, pontine and vestibular nuclei, extrapyrami- dal structures (substantia nigra, locus coeruleus and the pallidoluysian complex), as well as neuronal loss in motor cranial nerves, anterior horn cells and the posterior root ganglion. ${ }^{3,4}$ The cerebral and cerebellar cortex and inferior olivae are spared. ${ }^{5}$

From the Department of Neurology, National Yang-Ming University School of Medicine and National Defense Medical Center (B.S); Neurological Institute, Veterans General Hospital-Taipei (B.S., K.L.), Taipei. Taiwan, R.O.C.

RECEIVED MARCH 11, 1997. ACCEPTED IN FINAL. FORM JULY 10, 1997.

Reprint requests to: Bing-wen Soong, M.D., Ph.D., Neurological Institute, Veterans General Hospital-Taipei, Taipei, Taiwan, 11217, Republic of China 
The MJD locus was first mapped to chromosome 14q32.1 in Japanese families 5 and linkage was then confirmed in families of Portuguese pedigrees. ${ }^{6-8}$ The MJD gene, designated MJD, has since been isolated and characterized and the mutation has been demonstrated to be an expansion of a trinucleotide CAG repeat that lies at the 3 ' terminal of the coding region. ${ }^{9}$

There have been few reported studies of the peripheral nervous system in patients with spinocerebellar atrophy, which is partly attributable to its troublesome nosology..$^{10}$ Histological alterations in the peripheral nervous system of patients with MJD have never been reported. In order to investigate the nature and extent of these possible alterations, and to determine the factors influencing the severity of any associated pathological process, we subjected the median and tibial nerves of four patients with MJD to electrophysiological studies, and the sural nerves of these patients to both electrophysiological and histological studies.

\section{Materials and Methods}

\section{Subjects}

MJD was diagnosed in four patients from four different families, and these patients were selected for study (patients 1, 3 were male; 2 and 4 were female). At the time of selection the patients' ages ranged from 24 to 66 years (mean \pm SD $33 \pm 11$ ), and their duration of symptoms and signs ranged from 6 to 22 years (mean \pm SD $12 \pm 9$ ) (Table 1). Their CAG repeat numbers in the MJD chromosome ranged from 64 to 78 units (mean \pm SD $72 \pm 6$ ). The age at onset was based on information provided by the patient or close relatives. Informed consents were obtained from all subjects who participated in the study.

\section{Electrophysiological Studies}

Electrophysiological studies were performed using a Medlec MS25 electromyograph. Maximal motor nerve conduction velocity $(\mathrm{NCV})$ of the right tibial nerve, the amplitude of compound motor action potential (cMAP) of the right abductor hallucis, and the amplitude of the sensory action potential (SAP) of the right sural and median nerves were measured using surface electrodes. Distal sensory latencies (DL) were measured at a distance of $14 \mathrm{~cm}$ between the stimulating and recording electrodes. Needle EMG studies were carried out to collect evidence of acute denervation.

\section{Morphology and Morphometry}

A sural nerve fascicular biopsy $(2 \mathrm{~cm})$ was performed behind the lateral malleolus under local anesthesia. Specimens were fixed in $2.5 \%$ glutaraldehyde in $0.05 \mathrm{M} \mathrm{Na}$ cacodylate buffer, postfixed in $1 \%$ osmium tetraoxide and processed to Araldite. ${ }^{.1}$ Transverse sections of $1 \mu \mathrm{m}$ thickness were stained with toluidine blue. A light microscope with image analyzer (minimagiscan/ 1AS25/IV25, Joyce-Loebl, Newcastle, UK), was used to measure fascicular area, size of myelinated fibers and axons, and perimeters magnification 1600x. Five non-MJD individuals with Dupuytren's contracture, Bethlem myopathy, cerebral infarction, spinal muscular atrophy, and nonspecific complaints, respectively, with ages ranging from 23 to 65 years (mean \pm SD $44 \pm 19$ ) and CAG repeat numbers $22 \pm 7$ (mean $\pm \mathrm{SD}$ ) were selected as controls.

\section{Statistical Methods}

The association between CAG repeat size on the affected chromosomes of patients and fiber density of the sural nerves, percentage of large myelinated fibers, and the results of sensory and motor nerve conduction studies were evaluated by Pearson correlation analysis. The patient values were considered abnormal when they exceeded the mean \pm 2 SD values of controls.

\section{ReSULTS \\ Clinical and Molecular Studies}

The clinical symptoms, age at onset, duration of the disease and CAG repeat number of the MJD gene of these four patients are shown in Table 1.

\section{Neurophysiological Studies}

The sensory potentials were undetectable in three of the four patients (Table 1). Patients with absent sural nerve action potentials also exhibited abnormal median nerve sensory action potentials (data not shown). In the remaining one patient, who had only 64 CAG repeats in the MJD gene, both DL and SAP amplitude were normal.

The amplitudes of cMAP were markedly diminished in patient 1 , and mildly so in patient 2 . Both of these patients had higher CAG repeat numbers, with $78 \mathrm{CAG}$ repeats in patient 1 and $75 \mathrm{CAG}$ repeats in patient 2 (Table 1). However, the motor NCV was only slightly reduced in the first patient, who had the highest CAG repeat number (78) and was a juvenile (less than

Table 1: Clinical Parameters, Sural Nerve Findings, and Nerve Conduction Studies in Four Subjects with Machado-Joseph Disease.

\begin{tabular}{|c|c|c|c|c|c|c|c|c|c|c|}
\hline \multirow{2}{*}{$\begin{array}{c}\text { Case } \\
\text { Number }\end{array}$} & \multirow{2}{*}{$\begin{array}{l}\text { Clinical } \\
\text { Features }\end{array}$} & \multirow{2}{*}{$\begin{array}{c}\text { Age at } \\
\text { Onset (yr) }\end{array}$} & \multirow{2}{*}{$\begin{array}{c}\text { Duration } \\
(\mathbf{y r})\end{array}$} & \multirow{2}{*}{$\begin{array}{c}\text { CAG } \\
\text { Number }\end{array}$} & \multirow{2}{*}{$\begin{array}{c}\text { Fiber } \\
\text { Density }\end{array}$} & \multirow{2}{*}{$\begin{array}{c}\text { Fiber }>7 \mu \mathrm{m} \\
(\%)\end{array}$} & \multicolumn{2}{|c|}{ Sensory } & \multicolumn{2}{|c|}{ Motor } \\
\hline & & & & & & & DL (msec) & $\dot{S A P}(\mu V)$ & $\mathbf{c M A P}(\mathbf{m V})$ & $\mathrm{NCV}(\mathrm{m} / \mathrm{sec})$ \\
\hline 1 & $\mathrm{~A}, \mathrm{P}, \mathrm{V}, \mathrm{O}, \mathrm{M}$ & 18 & 6 & 78 & 3,146 & 27.6 & NR & NR & 1.3 & 33.2 \\
\hline 2 & $\mathrm{~A}, \mathrm{P}, \mathrm{V}, \mathrm{O}, \mathrm{M}$ & 35 & 19 & 75 & 5,104 & 13.7 & NR & NR & 5.0 & 49.7 \\
\hline 3 & $\mathrm{~A}, \mathrm{P}, \mathrm{V}, \mathrm{O}$ & 44 & 22 & 72 & 6,021 & 22.6 & NR & NR & 8.0 & 47.1 \\
\hline 4 & $\mathrm{~A}, \mathrm{P}$ & 38 & 4 & 64 & 9,547 & 40.2 & 2.66 & 15 & 15.0 & 53.0 \\
\hline \multirow[t]{2}{*}{ Controls } & & & & $22 \pm 7$ & $6,780 \pm 791$ & $41.7 \pm 8.7$ & $3.0 \pm 0.3$ & $12.5 \pm 5.2$ & $13.1 \pm 5.0$ & $50.5 \pm 5.3$ \\
\hline & & & & $(n=200)$ & $(\mathrm{n}=5)$ & $(n=5)$ & $(\mathrm{n}=$ & & $(n=$ & 68) \\
\hline
\end{tabular}

$A=$ ataxia, $P=$ pyramidal tract signs, $V=$ loss of vibration, $O=$ ophthalmoplegia, $M=$ muscular atrophy

$\mathrm{DL}=$ distal latency, $\mathrm{SAP}=$ sensory action potential amplitude of the right sural nerve

cMAP = compound motor action potential of the right abductor hallucis

$\mathrm{NCV}=$ nerve conduction velocity of the right tibial nerve

$\mathrm{NR}=$ no response 
20 years of age) at onset. The motor NCVs were normal in the other three patients. The motor nerve conduction studies performed on the right peroneal, median and ulnar nerves revealed no evidence of conduction slowing or blockade.

Needle EMG studies revealed evidence of acute denervation in patients one and two. All in all, three of the four MJD patients examined showed a peripheral nerve disorder.

\section{Light Microscopy and Morphometric Studies}

A clear loss of myelinated fibers was the main finding of light microscopy in two out of four patients (Table 1; Figure 1). None of the patients had abnormalities in the peri- or epineurium. Light microscopy failed to detect myelin changes, onion bulb formation or significant caliber variation in any of the patients.

The distribution of fiber diameter of the distal sural nerves was unimodal and histograms suggested a significant loss of fibers, especially large myelinated fibers in three of four patients (Figure 2).

Correlation analyses revealed a close relationship between CAG number and myelinated fiber density and between age at onset and motor NCV (Table 2).

\section{Discussion}

Electrophysiological and histological studies in patients with MJD demonstrated that the peripheral nervous system was affected in the majority of the patients. Among these four patients, three $(75 \%)$ had a decrease in sensory potential amplitude, two $(50 \%)$ had a reduction in cMAP amplitude, two (50\%) had evidence of acute denervation in needle EMG, and only one (25\%) had a mild decrease in motor conduction velocity (Table 1). Such data are suggestive of a sensory and motor neuropathy which affects axons but does not result in remarkable demyelination. Similar electrophysiological results were obtained by Carenini et al. ${ }^{12}$ in 11 patients with olivopontocerebellar atrophy (OPCA) (75\% of their patients showed a decrease in amplitude of SAP) and by Bennet et al. ${ }^{13}$ in four patients with OPCA $(75 \%$ showed an absence of sural nerve potential, $25 \%$ had a decrease in conduction velocity). It is of interest to compare our electrophysiological data with the observations made by Caruso et al. ${ }^{14}$ in patients with Friedreich's ataxia. They demonstrated that the most constant alterations were a severe loss of sensory fibers and a loss of motor units with only slight slowing of conduction velocity. These alterations did not appear to be related to the duration of the disease or the age at onset. While the reported loss of sensory fibers has been more severe in cases of Friedre-
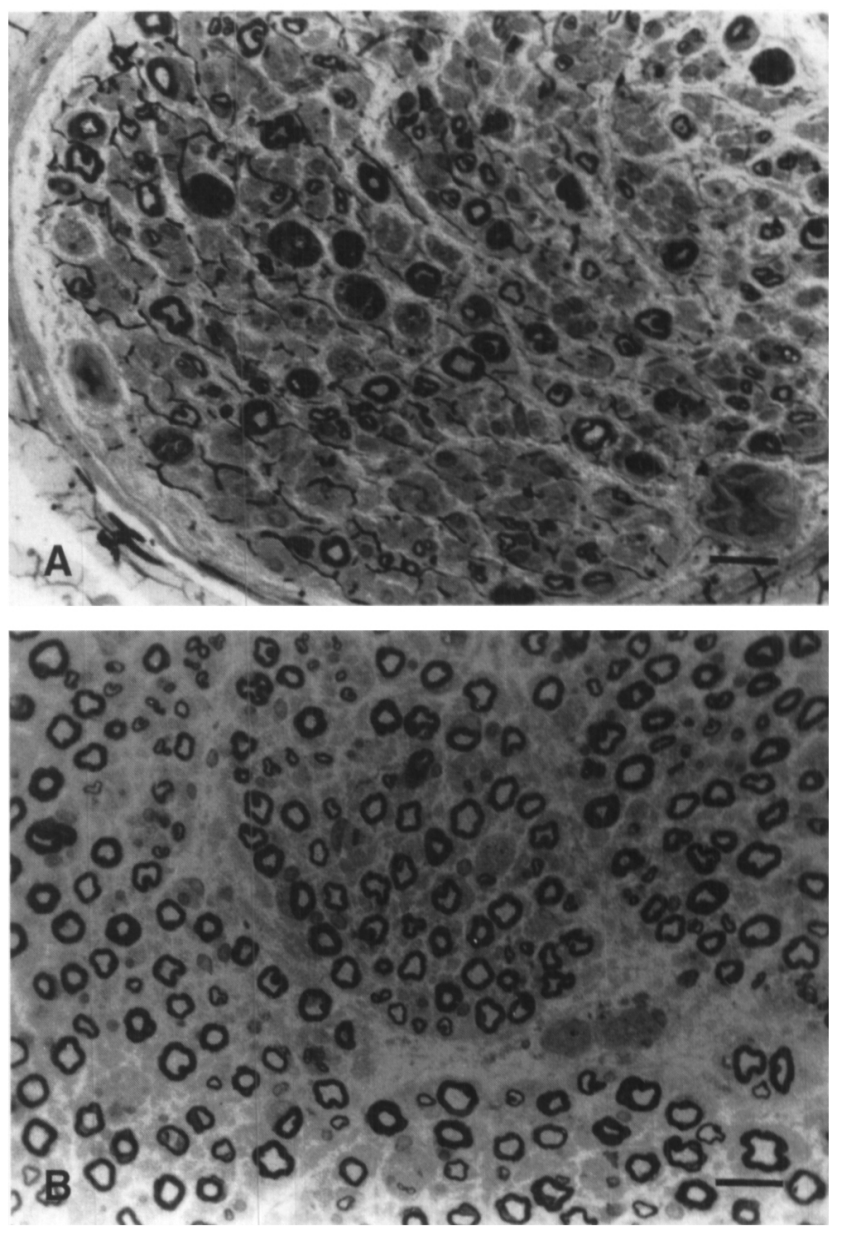

Figure 1: Light microscopy of distal sural nerves in (A) patient I (24 years of age) with Machado-Joseph disease and $(B)$ a normal control (25 years of age). Note the loss of fibers in $(A)$, especially large myelinated fibers. One-micron Epon section, toluidine blue stain $\times 40, B a r=$ $10 \mu m$.

ich's ataxia than in the MJD patients of this study, the distribution as well as the magnitude of the other electrophysiological alterations appear to be similar in these two diseases.

Pathological changes were found in the distal sural nerve biopsies of three of the four patients. Two of these patients had higher CAG repeat numbers ( 78 and 75 , respectively) and showed a clear axonal loss. The third specimen was from a patient with a medium repeat number (72) who had a fiber

Table 2: Correlation of Clinical Parameters, Electrophysiological Findings, and Morphometry in Machado-Joseph Disease.

\begin{tabular}{|c|c|c|c|c|c|c|}
\hline . & $\begin{array}{c}\text { Duration } \\
\qquad-\end{array}$ & $\begin{array}{l}\text { CAG Number } \\
\mathbf{r}\end{array}$ & $\begin{array}{l}\text { Fiber Density } \\
\mathbf{r}\end{array}$ & $\begin{array}{c}\text { Fiber }>7 \mu \mathrm{m} \% \\
\mathbf{r}\end{array}$ & $\underset{\mathbf{r}}{\text { Motor }}$ & $\begin{array}{c}\text { Motor NCV } \\
\text { r }\end{array}$ \\
\hline Age at Onset & 0.57 & -0.62 & 0.66 & -.04 & 0.89 & 0.97 \\
\hline Duration & & 0.29 & -.024 & -.081 & 0.58 & 0.69 \\
\hline CAG Number & & & -.099 & -0.70 & -0.46 & -0.47 \\
\hline Fiber Density & & & & 0.64 & 0.47 & 0.53 \\
\hline Fiber $>7 \mu \mathrm{m} \%$ & & & & & 0.01 & -0.26 \\
\hline Motor cMAP & - $\quad--$ & $\ldots-\ldots$ & $\ldots \ldots$ & $\ldots .$. & - & 0.81 \\
\hline
\end{tabular}




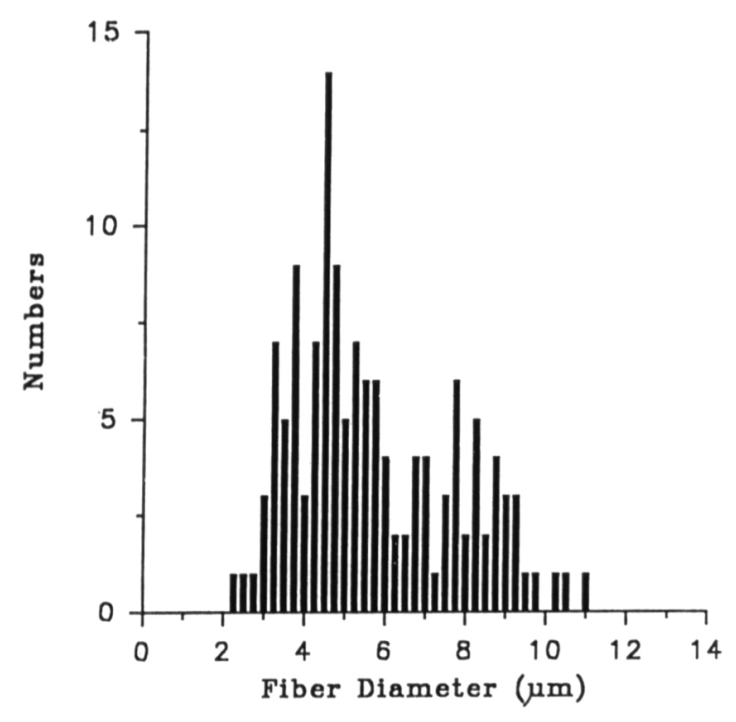

A

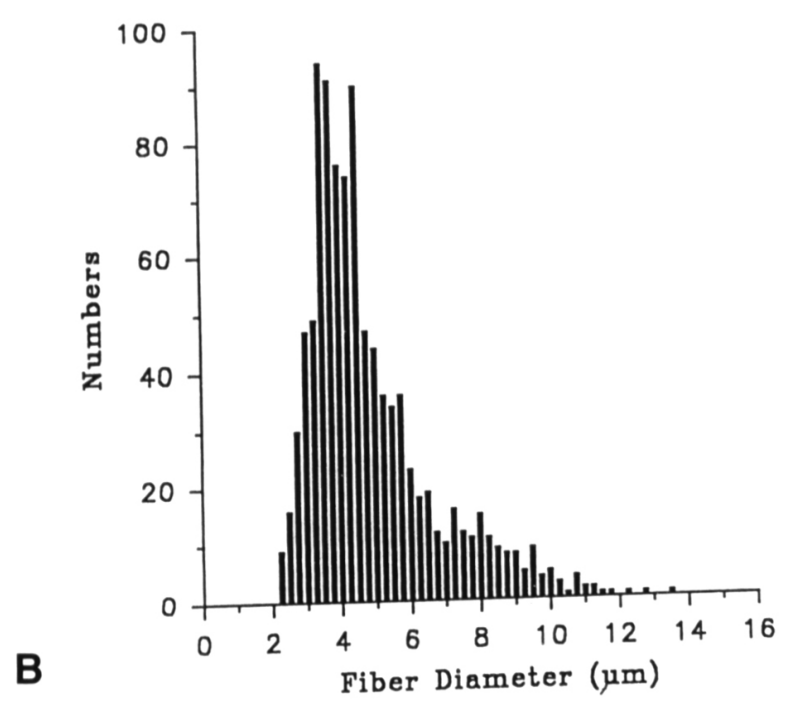

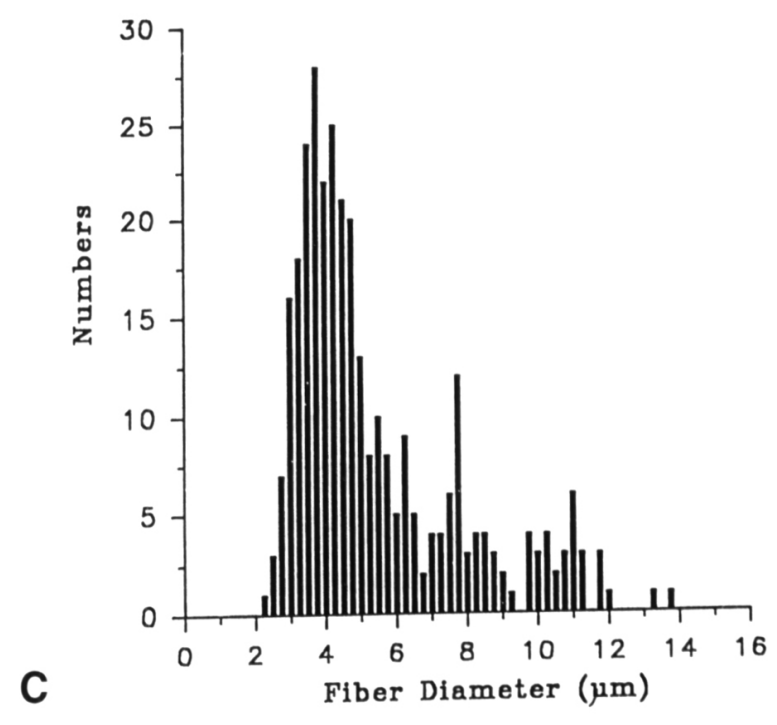

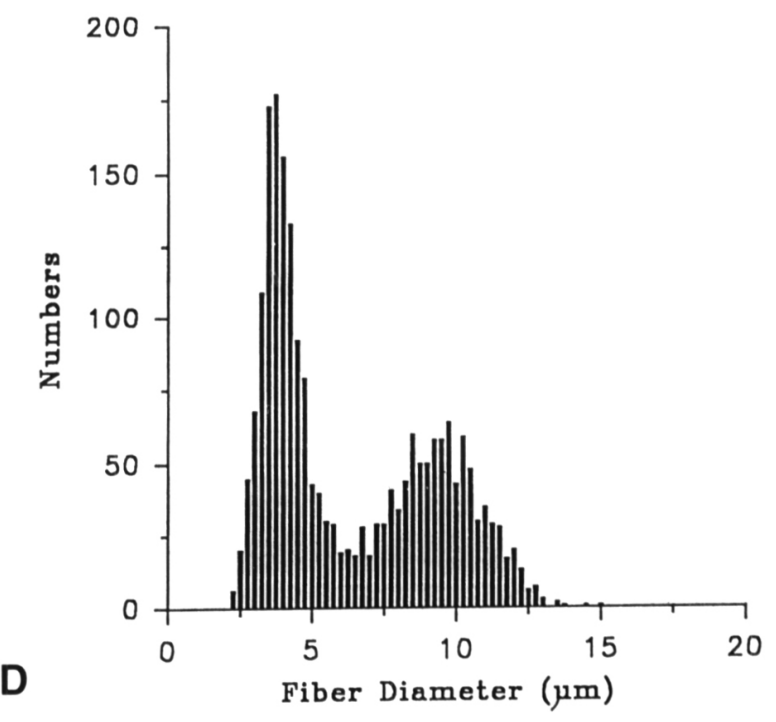

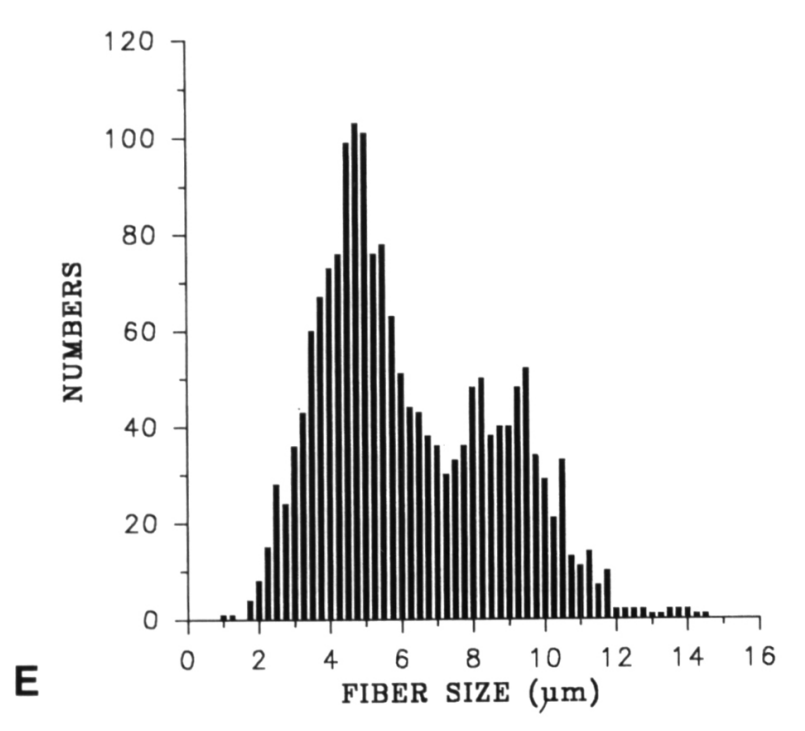

Figure 2: Morphometry of distal sural nerves in subjects $I(A), 2(B), 3(C), 4(D)$ and a normal control (E): $X$-axis: fiber diameters ( $\mu m) ; Y$-axis: myelinated fiber number per lum of diameter $/ \mathrm{mm}^{2}$. The large myelinated fibers $(>7 \mu \mathrm{m})$ are lost and the histograms are unimodal in subjects 1,2 and 3 . 
density in the lower limit of the normal distribution (Table 1). Teased fiber analysis and EM studies were not carried out. Thus, it is possible that some component of demyelination or changes in unmyelinated fibers could have been missed. However, in the morphometric measurements, all three pathological sural nerve specimens demonstrated a clear reduction of large myelinated fibers (Figure 2). Bennet et al. ${ }^{13}$ and Wadia et al. ${ }^{15}$ reported a form of neuropathy which preferentially affects myelinated fibers of large diameter in patients with OPCA. In this study, the histological findings in patients with MJD were similar to those described in Friedreich's ataxia. ${ }^{16}$ Inonue, Hirano and Hassin reported histometrical examination of an autopsied patient with Friedreich's ataxia, which showed severe loss of large myelinated fibers in the posterior spinal root and large dorsal root ganglion (DRG) cells, suggesting that the large DRG cells correspond to the large myelinated fibers of the sensory peripheral nerve. ${ }^{16}$ The sensory neuropathy found in patients with MJD may be attributed to an excessive, progressive neuronal cell death in dorsal root ganglia. Thus, in this study, MJD was not restricted to the motor system but frequently involved distal (peripheral) projections of the large myelinated sensory axon, especially when the CAG repeat number was above 70 .

Previously a linear correlation was found between the age at onset and the number of CAG repeats. ${ }^{2}$ However, this correlation was not perfect. The number of CAG repeats only accounted for approximately $60 \%$ of the variability in age at onset. A familial factor independent of CAG repeat length is known to influence age at onset of MJD. ${ }^{17}$ Patient 4 , who had a lower number of CAG repeats (64), likely came from a family with such a familial factor which caused onset at an unusually early age. In this study, we observed that the severity of the pathological changes in the sural nerves was influenced (accounting for $98 \%$ of the variability) by the number of CAG repeats in the MJD gene, but was not influenced by the age at onset or disease duration (Table 2). The relationship between the CAG repeats and the quantitative pathological findings is interesting. It is speculated that a rise in CAG repeat number might lead to increased toxicity of the MJD gene product which subsequently accounts for more neuronal loss in the DRG cells. The loss of large myelinated fibers is not likely the result of a progressive degenerative process which is proportionate to the duration of the disease.

In conclusion, both electrophysiological and histological findings in our patients with MJD indicated loss of the large peripheral nerve fibers, suggesting that the peripheral nervous system was frequently affected in MJD. These findings are similar to those seen in Friedreich's ataxia. Moreover, the severity of these changes is related to the length of pathological expansion of CAG repeats in the MJD gene. Therefore, the number of CAG repeats is related not only to the age at onset, but also to some extent to the pathological changes in the peripheral nerves. The progressive clinical worsening of MJD could be due to alterations advancing in other structures outside the peripheral nerves. Further studies of a much larger sample size are needed to verify these observations.

\section{ACKNOWLEDGEMENT}

We thank Ms. Wen-yuan Shen for her assistance with the statistical analyses. We also gratefully acknowledge research support from the National Science Council, Republic of China (Grant NSC 85-2331B075-065) and the Veterans General Hospital-Taipei (grant 354).

\section{REFERENCES}

1. Harding AE. Clinical features and classification of inherited ataxias. Adv Neurol 1993; 61: 1-14.

2. Soong BW, Cherng CH, Liu RS, Shan DE. Machado-Joseph disease: clinical, molecular, and metabolic characterization in Chinese kindreds. Ann Neurol 1997; 41: 446-452.

3. Coutinho P. Review of neuropathological findings in MachadoJoseph disease: clinico-pathological correlation. Presented at the NIH: Research Initiatives on Machado-Joseph Disease, Bethesda, 1991, June 3-4.

4. Sudarsky L, Corwin L, Dawson DM. Machado-Joseph disease in New England: clinical description and distinction from the olivopontocerebellar atrophies. Mov Dis 1992; 7: 204-208.

5. Takiyama Y, Nishizawa M, Tanaka $\mathrm{H}$, et al. The gene for MachadoJoseph disease maps to human chromosome 14q. Nature Genet 1993; 4: 300-304.

6. Sequeiros J, Silveira I, Maciel P, et al. Genetic linkage studies of Machado-Joseph disease with chromosome 14q STRPs in 16 Portuguese-Azorean kindreds. Genonics 1994; 21: 645-648.

7. St George-Hyslop P, Rogaeva E, Hutterer J, et al. Machado-Joseph disease in pedigrees of Azorean descent is also linked to chromosome 14. Am J Hum Genet 1994; 55: 120-125.

8. Twist EC, Casaubon LK, Ruttledge MH, et al. Machado-Joseph disease maps to the same region of chromosome 14 as the spinocerebellar ataxia type 3 locus. J Med Genet 1995; 32: 25-31.

9. Kawaguchi Y, Okamoto T, Taniwaki M, et al. CAG expansions in a novel gene for Machado-Joseph Disease at chromosome 14q32.1. Nature Genet 1994; 8: 221-227.

10. Rossi A, Ciacci G, Federico A, Mondelli M, Rizzutto N. Sensory and motor peripheral neuropathy in olivopontocerebellar atrophy. Acta Neurol Scand 1986; 73: 363-371.

11. Lin KP, Yeh TP, Wang S, et al. Polyneuropathy associated with acute monoblastic leukemia, a case report. Chin Med J (Taipei) 1996; 58: 435-438.

12. Carenini L, Finocchiaro G, Di Donato S, Visciani A, Negri S. Electromyography and nerve conduction study in autosomal dominant olivopontocerebellar atrophy. J Neurol 1984; 231 : 34-37.

13. Bennet RH, Ludvigson P, DeLeon G, Berry G. Large fiber sensory neuronopathy in autosomal dominant spinocerebellar degeneration. Arch Neurol 1984; 41: 175-178.

14. Caruso G, Santoro L, Perretti A, et al. Friedreich's ataxia: electrophysiological and histological findings in patients and relatives. Muscle Nerve 1987; 10: 503-515.

15. Wadia N, Irani P, Mehta L, Purohit A. Evidence of peripheral neuropathy in a variety of heredo-familial olivopontocerebellar degeneration frequently seen in India. $I n$ : Sobue I, ed. Spinocerebellar Degenerations. Tokyo, Japan: University of Tokyo Press, 1980: 239-250.

16. Inonue K, Hirano A, Hassin J. Friedreich's ataxia selectively involves the large neurons of the dorsal root ganglion. (Abstract) Ann Neurol 1979; 6: 150.

17. DeStefano AL, Cupples A, Maciel P, et al. A familial factor independent of CAG repeat length influences age at onset of Machado-Joseph disease. Am J Hum Genet 1996; 59: 119-127. 